\title{
A CARACTERIZAÇÃO DA ATIVIDADE EMPRESÁRIA: IDENTIFICAÇÃO DOS ELEMENTOS DE EMPRESA SOB A ÓTICA SISTÊMICA
}

\section{João Alberto da Costa Ganzo Fernandez}

Resumo: Este artigo apresenta a Teoria dos Sistemas como subsídio teórico para a concepção de um novo parâmetro para identificar a existência de uma empresa, fato que possui reflexos jurídicos importantes. Admitindo a empresa como um organismo autônomo, sua existência pode ser aferida pelo critério da essencialidade da figura física do empresário.

Palavras-chave: Atividade Empresária. Direito Empresarial. Empresa. Teoria da Empresa. Teoria dos Sistemas.

\section{INTRODUÇÃO}

Do ponto de vista legal, uma atividade econômica é considerada empresária no Brasil, se atender aos requisitos expressos no art. 966 do Código Civil, ou seja, deve ser uma atividade econômica, organizada, exercida profissionalmente para a

1 Aluno do Módulo III da Escola Superior da Magistratura do Estado de Santa Catarina (ESMESC). Advogado, Bacharel em Administração de Empresas, Mestre e Doutor em Engenharia Civil. Professor titular do IFSC - Instituto Federal de Tecnologia de Santa Catarina. E-mail: jganzo@terra.com.br 
produção ou a circulação de bens e serviços. Esses requisitos de empresarialidade foram herdados da Teoria da Empresa, contribuição italiana que representou um avanço no sentido de adaptar o ordenamento jurídico às mudanças ocorridas na estrutura econômica pós revolução industrial. Todavia os parâmetros definidos pelo legislador são eivados de subjetivismo, dificultando a tarefa do intérprete.

Assim, este artigo tem por escopo examinar quais são os critérios estabelecidos pela doutrina para caracterizar a atividade empresária sob diversos enfoques, discutir a sua importância no mundo jurídico, apresentando a Teoria dos Sistemas como subsídio teórico para a concepção de um novo parâmetro para identificar a existência de uma empresa.

\section{OS CONCEITOS DE EMPRESA}

Os últimos dois séculos foram marcados por uma multiplicação exponencial da riqueza mundial graças às empresas, organizações humanas que combinam eficientemente os fatores de produção de forma sinérgica e sistêmica para produzir e fazer circular bens e serviços.

Sempre existiram formas de trabalho organizadas e dirigidas. Porém, a acumulação de capital, a invenção de máquinas de produção em série e a expansão dos mercados pós-revolução industrial provocaram um desenvolvimento da atividade empresarial nunca antes visto. Porém até os dias de hoje os juristas debatem acerca do conceito de empresa. Esta seção discute as origens da teorização a respeito da empresa e os seus conceitos jurídicos e não jurídicos.

\subsection{A Teoria da Empresa}

Concebida em 1942, na Itália fascista, para melhor disciplinar as atividades econômicas privadas, esse sistema, em complementação à Teoria dos Atos de Comércio, que remonta 
à França de Napoleão, incorporou no seu bojo todas as atividades de prestação de serviços e as ligadas à terra. Materializouse com a unificação parcial do Direito Comercial e do Direito Civil em um único diploma legal.

Waldírio Bulgarelli (1995, p.56) comenta as razões históricas que levaram o legislador italiano a essa mudança de paradigma:

Pressionado pela transformação do capitalismo comercial em capitalismo industrial, que tornara imprópria a assimilação do industrial ao comerciante para o fim de ser submetido ao estatuto deste, a intenção do legislador foi a de posicionar o industrial como empresário e, portanto, agente da produção, em igualdade de condições com o comerciante, produzindo-se em conseqüência uma reviravolta, ao substituir o sistema assentado no comerciante por outro baseado no empresário.

A doutrina brasileira já sinalizava desde a década de sessenta com as vantagens da Teoria da Empresa. De fato, como afirma Fábio Ulhoa Coelho (2007, p. 10), ela fora incorporada no projeto do novo Código Civil já em 1975. Durante os quase 30 anos que o Congresso levou para aprová-lo, diversas leis de interesse do direito comercial foram editadas inspiradas pela Teoria da Empresa. Destacam-se o Código de Defesa do Consumidor de 1990, a Lei de Locação Predial Urbana de 1991 e a Lei do Registro de Empresas de 1994.

\subsection{Conceitos não jurídicos de empresa}

A pesquisa no Dicionário Houaiss da Língua Portuguesa (Houaiss et al., 2007, p. 1.128), revela que a palavra empresa possui três significados distintos:

a) empreendimento para a realização de um objetivo (exemplo: as navegações portuguesas constituem empresas notáveis); b) organização econômica, civil ou comercial, constituída para explorar determi- 
nado ramo de negócio e oferecer ao mercado bens ou serviços; c) entidade jurídica, firma.

Para os economistas americanos Robert Hall e Marc Lieberman (2003, p.181), uma empresa, que a tradução brasileira ${ }^{2}$ denomina de firma de negócios, é "[...] uma organização especializada em produção, de propriedade de pessoas particulares e operada por elas mesmas".

Curtis Eaton e Diane Eaton (1999, p. 180), em sintonia com o conceito amplo de produção, acrescentam a prestação de serviços entre as atividades desenvolvidas pelas empresas. Segundo eles a empresa é "uma entidade que compra fatores de produção, ou insumos, e transforma-os em bens ou serviços, ou produtos para a venda".

Enzo Rulanni (1983, p. 16), com enfoque sistêmico, considera a empresa muito mais do que o lugar no qual pessoas, organização e ambiente se confrontam e interagem em alguma solução que os satisfaça. Para ele a empresa é, no âmbito da economia, sujeito que exprime próprios interesses e os faz valer no ambiente externo. Trata-se de um sistema organizado que vive simbioticamente em um sistema maior - o sistema econômico-social, onde desenvolve uma função limitada e bem determinada.

\subsection{Conceitos jurídicos de empresa}

O Código Civil Italiano, sob influência da Teoria da Empresa, tal como o Código civil Brasileiro, não conceitua a empresa, mas sim o empresário ${ }^{3}$, que é quem desenvolve atividade econômica, organizada, exercida profissionalmente para a produção ou a circulação de bens e serviços. Por dedução, a empresa é a atividade do empresário.

2 Tradução do inglês para o português de Luciana Michelino.

3 O conceito brasileiro, expresso no art. 966 do CC é tradução quase literal do conceito expresso no art. 2.082 do Código Civil Italiano de 1942, in verbis: "É imprenditore chi esercita professionalmente un attività economica organizzata al fine della produzione o dello scambio di beni o di servizi". (ITÁLIA, 1991). 
Segundo Fran Martins (1986, p. 27) a definição de empresa oriunda da Teoria da Empresa falha por ter sentido econômico e não jurídico. Complementa afirmando que ainda não existe um conceito jurídico para esta entidade. Opinião diversa é apresentada pelo italiano Gian Franco Campobasso (1997, p. 24). Para ele, é indubitável que o conceito de empresário expresso no Código Italiano reporta-se a um conceito econômico, e nem podia ser diferente, pois se trata da descrição de uma realidade econômica.

Porém são distintas as tarefas do economista e do operador do direito. $O$ primeiro analisa a função dos diversos atores da vida econômica no sistema de produção e distribuição da riqueza, enquanto o segundo está preocupado em fixar os requisitos mínimos necessários e suficientes que devem acontecer para que um dado sujeito seja exposto a uma dada disciplina: a disciplina dos empresários.

Ainda em relação ao conceito jurídico de empresa, é basilar a contribuição doutrinária do jurista italiano Alberto Asquini, um dos principais formuladores da Teoria da Empresa, publicada originalmente em 1943. Segundo Alberto Asquini (1996, p. 109-110) a empresa pode ser identificada por seu aspecto subjetivo, funcional, patrimonial (objetivo) e corporativo. No aspecto subjetivo a empresa é vista como o próprio empresário. No aspecto funcional, a empresa é vista como a própria atividade, ou seja, uma abstração. Fábio Ulhoa Coelho (2003, p. 1) considera que é este o conceito de empresa que a doutrina irá prestigiar. No aspecto patrimonial, empresa confunde-se com estabelecimento, que é o conjunto de bens que lhe dá materialidade. Por fim, no aspecto corporativo, empresa é uma instituição formada pelo empresário e seus empregados.

A tese de Asquini, no entender de Sylvio Marcondes $(1977, \text { p. 6) })^{4}$, " [...] resolveu uma pendência na doutrina italiana, dividida em inúmeras correntes, cada qual pretendendo que a sua fosse a verdadeira conceituação de empresa em termos jurí-

4 Autor do livro 'Direito de Empresa' do anteprojeto do Código Civil de 2002. 
dicos". Para ele, o conceito poliédrico de empresa tem perfeita aplicação no nosso direito, haja vista o exame de alguns preceitos legais brasileiros. ${ }^{5}$

Maria Helena Diniz (2006, p. 754) utiliza-se dos aspectos funcional e patrimonial descritos por Asquini, para definir empresa. Segundo o conceito operacional da autora, empresa é: "[...] a atividade organizada para produção e circulação de bens ou de serviços, desenvolvida por uma pessoa natural (empresário) ou jurídica (sociedade empresária), por meio de um estabelecimento".

\section{REFLEXOS JURÍDICOS DA CARACTERIZAÇÃO DA ATIVIDADE EMPRESÁRIA}

A caracterização de uma atividade como empresária possui conseqüências jurídicas importantes, principalmente nas áreas tributária, falimentar e civil. A seguir serão discutidos alguns aspectos destacados de cada um desses ramos do direito e que ilustram o alcance prático deste artigo.

\subsection{Aspectos destacados sob o prisma tributário}

O legislador conferiu às sociedades simples regime de tributação análogo às sociedades empresárias ${ }^{6}$. $\mathrm{O}$ mesmo se deu em relação ao empresário individual. Esse regime de tributação das pessoas jurídicas e equiparadas (empresário individual) diferencia-se do regime destinado às pessoas físicas, no qual está enquadrado o profissional autônomo. Enquanto este está sujeito ao pagamento do Imposto de Renda Pessoa Física ${ }^{7}$, Contribuição Previdenciária e ao recolhimento do Imposto Municipal sobre Serviços (ISS), aqueles devem pagar Imposto

5 Refere-se aos perfis subjetivo, presente no art. $2^{\circ}$, e objetivo, que aparece no art. 448, ambos da Consolidação das Leis do Trabalho (CLT).

6 Ver art. 129 da Lei 11.196/2005 (MP do bem) e art. 146 do Regulamento do Imposto de Renda, Decreto n. 3000/99.

7 A legislação do imposto de Renda permite o abatimento de despesas da atividade do autônomo (salário de secretária, aluguel, etc) se registradas em livro caixa. 
de Renda Pessoa Jurídica (IRPJ), Contribuição Social sobre o Lucro Líquido (CSLL), Programa de Integração Social (PIS), Contribuição para o Financiamento da Previdência Social (COFINS), Contribuição Previdenciária (INSS) e Imposto sobre Serviços (ISS) ${ }^{8}$. O Imposto de Renda da Pessoa Jurídica, por sua vez, pode incidir sobre o lucro real ou sobre o lucro presumido.

Porém, a Lei 9.249/95 estabeleceu, no art. 10ª a isenção do Imposto de Renda sobre os lucros ou dividendos distribuídos aos sócios ou acionistas, apurados a partir de janeiro de 1996. Isso significa que os rendimentos provenientes de lucros ou dividendos não são tributáveis, nem na fonte e nem na declaração do empresário (ou participante da sociedade simples). Evita-se, desta forma, uma possível bi-tributação. Cumpre esclarecer que a remuneração do trabalho do empresário, recebida na forma de pró-labore, é tributada da mesma forma que os rendimentos do autônomo.

De acordo com informações do Serviço Brasileiro de Apoio à Pequena e Média Empresa de São Paulo, de um modo geral, a empresa possui carga tributária menor que a do autônomo. Todavia, isso dependerá de uma série de fatores, tais como o faturamento e a atividade exercida. (SEBRAE/SP, 2007). Então, para pagarem menos impostos muitos prestadores de serviços de caráter personalíssimo constituem pessoa jurídica. Entretanto, por vezes, trata-se apenas de artifício para dissimular vínculo empregatício e burlar a legislação trabalhista e previdenciária.

Há, porém, situações em que a legislação tributária privilegia o trabalho autônomo. A jurisprudência catarinense apresenta casos recentes de clínicas médicas que entraram com ações de repetição de indébito para obter valores pagos, supostamente a maior, de ISS. Alegaram em juízo que, por não se considerarem empresas, deveriam recolher o ISS em valor fixo anual (como fazem os autônomos e sociedades simples) e não em alíquota incidente sobre o faturamento. Nos julgados pesqui-

8 Em Florianópolis/SC, a alíquota varia entre 2\% e 5\% (Código Tributário Municipal, art. 256), calculada sobre o valor do serviço. (FLORIANÓPOLIS/SC, 1997). 
sados $^{9}$, o entendimento predominante foi de negar provimento à argumentação dos autores, sob o fundamento de que as clínicas médicas demandantes perderam o caráter de sociedade simples, adquirindo o caráter empresarial. Os casos das clínicas médicas encontrados na jurisprudência são emblemáticos por evidenciar a postura do intérprete, que considera a realidade fática empresarial da atividade e não o que estava avençado no contrato social dos postulantes, todos registrados como sociedades simples.

De qualquer maneira, como aduz Jorge Rubem Folena de Oliveira (1999, p. 120), para o Direito Tributário, a empresa é vista como pessoa jurídica, ou seja, sujeito de direitos e obrigações.

\subsection{Aspectos destacados sob o prisma civil}

O exercício da atividade empresária cria ônus, obrigações e responsabilidades para quem a pratica. Entre as obrigações instituídas pelo Código Civil destacam-se o seu registro conforme determina o art. 967 do CC e a escrituração contábil, como dispõe o art.1.179 do CC.

No plano da responsabilidade civil, se o exercício da atividade empresária implicar por natureza riscos, estará sujeito à responsabilidade civil objetiva, nos termos do art. 927 do CC.

A caracterização da atividade como empresária implica também algumas questões burocráticas. Segundo Fábio Ulhoa Coelho (2005, p. 20) as empresas estão obrigadas às formalidades societárias periódicas, como a reunião anual dos sócios para aprovação de contas (sociedades limitadas); não admitem a figura do sócio que integraliza sua participação com serviços (CC, art. 997, V) e se submetem à proibição de formação de sociedade entre sócios casados em regime de comunhão universal e separação obrigatória (CC, art. 977).

9 SANTA CATARINA, Tribunal de Justiça de Santa Catarina: Apelação Cível n. 2006.003326-5, da Capital;, Apelação Cível n. 2006.004624-8, de Balneário Camboriú e Embargos Infringentes n. 2006.009564-3, da Capital. 
No que diz respeito ao uso da autonomia patrimonial da pessoa jurídica para a realização de fraudes, o CC, art. 50, autoriza o Poder Judiciário a ignorá-la e responsabilizar o sócio por obrigação que cabia à empresa.

\subsection{Aspectos destacados sob o prisma falimentar}

O princípio da preservação da empresa, cujo valor básico prestigiado é o da conservação da atividade e não do empresário, faz com que a atividade empresária receba um tratamento diferenciado quando está em dificuldades financeiras.

Com esta filosofia, o legislador brasileiro modernizou o estatuto falimentar promulgando em 2005 a nova Lei de Falências (Lei n. 11.101/05), cuja marca principal é a instituição da recuperação judicial, muito mais eficiente no seu propósito que a antiga concordata, pois alcança somente os empresários cuja atividade econômica possa realmente ser reorganizada. (COELHO, 2005, p.39).

Segundo Fábio Ulhoa Coelho (2005, p.14), são quatro as atividades econômicas não empresariais que não podem pleitear o benefício da recuperação judicial, nem falir: quem presta serviço diretamente, mas não organiza empresa, os profissionais intelectuais, os empresários rurais não registrados na Junta Comercial e as cooperativas. Ou seja, todos que não são considerados empresários à luz do art. 966 do CC, inclusive as sociedades simples.

$\mathrm{O}$ art. $2^{\circ}$ da Lei de Falências exclui também algumas modalidades de empresa, como as empresas públicas e de economia mista, além das instituições financeiras.

Portanto, em regra, a caracterização da atividade como empresária é que permite o enquadramento no novo regime falimentar. 


\section{OS ELEMENTOS DE EMPRESA CONFORME O ART. 966 DO CÓDIGO CIVIL}

Como já comentado, o art. 966 do CC define quem é empresário e quais são os elementos de empresa:

Art.966. Considera-se empresário quem exerce profissionalmente atividade econômica organizada para a produção ou a circulação de bens ou de serviços. Parágrafo Único. Não se considera empresário quem exerce profissão intelectual, de natureza científica, literária ou artística, ainda com o concurso de auxiliares ou colaboradores, salvo se o exercício da profissão constituir elemento de empresa. (BRASIL, 2002).

Percebe-se na leitura do texto legal a opção do legislador em subjetivar o conceito. Não há critérios claros que definam o que venha a ser uma atividade econômica, quando que ela é exercida profissionalmente e a partir de que condições ela passa a ser considerada organizada. Nesta seção, será feita uma análise de cada um dos elementos de empresa contidos no art. 966 do CC.

\subsection{0 profissionalismo}

A atividade econômica deve ser exercida com habitualidade (sistematicamente) e não ocasionalmente. De acordo com Antonino Romeo (1985, p.18) habitualidade não significa continuidade, logo, pode ser sazonal, como por exemplo, a gestão de um estabelecimento balneário. Compartilha desta idéia Campobasso (1997, p.33) ao afirmar que para ser profissional basta que a atividade repita-se constantemente de acordo com a sua própria cadência.

Dílson Lange (2005, p.90) diverge deste entendimento. Para ele o trabalho sazonal não caracteriza a habitualidade. Cita como exemplo um veranista, que todo ano compra nas indústrias instaladas nas praias de Santa Catarina e revende aos 
amigos, como forma de ajudar nas despesas de suas férias. Este cidadão, para Lange, não pode ser considerado empresário, pois lhe falta a habitualidade.

Uma outra característica importante do profissionalismo, segundo Antonino Romeo (1985, p.18), é que a atividade econômica deve satisfazer a outras pessoas, ou seja, as empresas produzem para o mercado. $\mathrm{O}$ autor também coloca que o profissionalismo pressupõe a assunção do risco por parte do empreendedor. Este age em nome próprio. Para o autor italiano, não são empreendedores aqueles que agem em nome de outrem, como os representantes comerciais. Fábio Ulhoa Coelho (2007, p.11) explica melhor o conceito da pessoalidade: "O empresário, no exercício da atividade empresarial, deve contratar empregados. São estes que, materialmente falando, produzem ou fazem circular bens ou serviços”.

Contudo, para Coelho, estes dois pontos, apesar de bem destacados pela doutrina não são os mais importantes. Para ele, o aspecto mais importante do profissionalismo é o monopólio das informações que o empresário detém sobre o produto ou serviço objeto de sua empresa. Porque é um profissional, o empresário tem o dever de conhecer todas as facetas, características, qualidades e defeitos dos produtos ou serviços que apresenta para o mercado. Gian Franco Campobasso (1997, p.35) complementa os conceitos em comento afirmando que também a execução de uma única empreitada, como por exemplo, a construção de um edifício, deve ser considerada como profissional. Pela sua relevância econômica, implica a execução de operações múltiplas e complexas e da utilização de um aparato produtivo adequado a excluir o caráter ocasional e não coordenado deste tipo de ato econômico isolado.

\subsection{A atividade econômica organizada}

Atividade econômica, na acepção da palavra, significa atividade produtiva (bens ou serviços). $\mathrm{O}$ trabalho remunerado, 
portanto, não deixa de ser uma atividade econômica, cujo resultado pode ser o salário, para o trabalhador empregado, ou os honorários (pró labore), quando se tratar de profissionais liberais. Tratando-se de empresas, o resultado da atividade econômica aparece na forma de lucro.

Para Hal Varian (1999, p.345) os lucros são definidos, na economia, como receitas menos custos. O objetivo é maximizar o valor presente do fluxo de lucros que a empresa deve gerar, pois assim estará aumentando o seu valor de mercado. A avaliação da empresa através do método do valor presente (fluxo de receitas menos despesas descontadas a uma certa taxa de oportunidade) possibilita a inclusão do fundo de comércio no resultado final da avaliação, o que não é possível quando se avaliam apenas os bens materiais da empresa por qualquer outro método (custo de reprodução, comparativo, etc).

Ensinam Joseilton Rocha e Paulo Selig (2001, p.2) que o lucro pode ser entendido, também, como a remuneração do capital investido.

$\mathrm{Na}$ organização empresarial, é necessário que apareça sempre alguma vantagem em forma de lucro. Pois, caso contrário, a empresa será abandonada pelo capitalista, via de regra muito exigente. $\mathrm{O}$ fim lucrativo pode ser um caráter normal da atividade econômica empreendedora, porém não pode ser considerado condição para a existência da empresa. De fato, também as sociedades simples (não empresárias) podem ter o lucro como escopo. $\mathrm{O}$ art. 997 do CC que trata da constituição de tais sociedades exige, em seu inciso VII, que seja mencionada no contrato social a participação de cada sócio nos lucros e nas perdas.

É plausível que exista sociedade simples, formada por dois sócios, na qual um é sócio capitalista que fornece os instrumentos de trabalho e a sede física da sociedade e o outro, profissional liberal que presta seus serviços. Ambos dividem o lucro resultado da atividade econômica social. Logo, a finalidade de lucro não pode ser considerada característica exclusiva das atividades empresárias. 
Analisando a questão por outro ângulo, Dílson Lange (2005, p. 24) assevera que: "A busca pelo lucro é uma das qualidades inerentes à atividade empresarial e conseqüentemente se sujeita a uma série de tributos federais, estaduais e municipais". Já na sociedade simples, segundo o mesmo autor: "o lucro não é fator indispensável”. Ou seja, para ele, o lucro é fator indispensável à atividade empresária. Há entendimento no Superior Tribunal de Justiça (STJ) de que o fim lucrativo caracteriza a atividade empresária, como é possível depreender do seguinte julgado transcrito:

(...) Por exercício profissional da atividade econômica, elemento que integra o núcleo do conceito de empresa, há que se entender a exploração de atividade com finalidade lucrativa. (BRASIL, 2004)

Antonino Romeo (1985, p.18), divergindo desta opinião, pondera que também são considerados empreendedores aqueles que não perseguem o lucro como finalidade, como as empresas públicas, as sociedades cooperativas e os fundos de pensão.

\subsection{A produção e circulação de bens e serviços}

Produção, no entendimento de Robert Hall e Marc Lieberman (2003, p. 181), "é o processo de combinar insumos para fazer produtos". Os insumos compreendem a terra, o capital, o trabalho e a tecnologia, que é a maneira pela qual esses elementos podem ser combinados para produzir produtos. Entretanto, como bem ressalta Henri Guitton (1961, p.213), o conceito de produção é muito mais amplo do que simplesmente combinar insumos. Usando exemplo do próprio autor, ninguém refuta a idéia de que a manufatura de um relógio é uma produção. Porém, não é tão claro para a maioria das pessoas que o transporte e o comércio desse relógio possam também ser considerados como atividades produtivas. E o são, pois de nada adianta criar o relógio se ele não chega até quem lhe atribuir 
utilidade (consumidor). Logo, transportar e comerciar também são atividades produtivas.

Para que este conceito fique ainda mais evidente, considere-se outro exemplo. Um mineiro que extrai uma pepita de ouro está produzindo um bem. Ele não criou nada, apenas extraiu da terra algo que estava escondido e lhe deu utilidade. Mas não se pode refutar a idéia de que ele produziu. Pois assim procede o comerciante, quando extrai da indústria o relógio e o coloca a disposição do consumidor final. Nesta esteira, Henri Guitton, (1961, p. 214) afirma: "Há produção quando há criação de utilidades inerentes, incorporadas aos objetos materiais, isto é, quando o mundo ou a comunidade vê aumentar seus produtos materiais".

Esta discussão é relevante porque, de acordo com o conceito anteriormente aposto, as atividades liberais autônomas também devem ser consideradas produtivas, a despeito de não serem empresárias, já que os serviços prestados por estes profissionais são importantes para que os bens materiais sejam produzidos (saúde dos trabalhadores, projeto das fábricas, aplicação de leis, etc).

Com a correta compreensão do que seja uma atividade produtiva, é importante retornar a discussão dos critérios que caracterizam uma atividade como empresária.

\section{A TEORIA DOS SISTEMAS E A ATIVIDADE EMPRESÁRIA}

\subsection{A Teoria dos Sistemas e as organizações}

A Teoria Geral dos Sistemas (TGS) surgiu com os trabalhos do biólogo austríaco Ludwig Von Bertalanffy, publicados entre 1950 e 1968. Segundo a TGS os sistemas vivos, sejam indivíduos ou organizações, são analisados como "sistemas abertos", mantendo um contínuo intercâmbio de matéria/ 
energia/informação com o ambiente. (CHIAVENATTO, 1993, p.749).

Segundo essa teoria, a empresa é vista como um sistema organizador e transformador de inputs trazidos do ambiente em outputs para o mesmo ambiente. (AIROLDI et al., 1989, p.73).

De acordo com o princípio da homeostase ${ }^{10}$, as organizações, como todo sistema aberto, procuram manter uma certa constância no intercâmbio de energia importada e exportada do ambiente, assegurando o seu caráter organizacional e evitando o processo entrópico (desintegração). Leciona Idalberto Chiavenatto (1993, p.775) que:

Enquanto em teoria de sistemas fala-se em homeostasia dinâmica (ou manutenção de equilíbrio por ajustamento constante e antecipação), usa-se o termo dinâmica de sistema em organizações sociais: o sistema principal e os subsistemas que o compõe são caracterizados por sua própria dinâmica ou complexo de forças motivadoras, que impelem uma determinada estrutura para que ela se torne cada vez mais aquilo que basicamente é. Para sobreviver (e evitar entropia), a organização social deve assegurar-se de um suprimento contínuo de materiais e pessoas (entropia negativa).

A empresa por este enfoque é, a semelhança de um ser vivo, um sistema que quanto mais se torna complexo, mais autonomia ganha em relação à sua própria auto-organização. Dentro desta concepção, a personalidade jurídica da empresa representa algo mais que a união de pessoas físicas em sociedade, representa o próprio sistema.

10 Conceito extraído da Teoria dos Sistemas que significa a propriedade de um sistema aberto de regular o seu ambiente interno de modo a manter uma condição estável, mediante múltiplos ajustes de equilíbrio dinâmico controlados por mecanismos de regulação inter-relacionados. (CHIAVENATTO, 1993, p. 765) 


\subsection{A essencialidade da força laborativa do empresário}

Maria Helena Diniz (2006, p.755) considera que a figura física do empresário, como organizador dos fatores de produção, é essencial à continuidade da existência da empresa. Todavia, uma vez organizada a empresa, nada impede que o empreendedor delegue a sua gerência a outros indivíduos com aptidão administrativa. Nesta hipótese, a empresa continuará existindo como entidade autônoma e independente. Esse é o destino inevitável das grandes corporações. Nessas empresas, muitas delas transnacionais, os empreendedores originais já morreram faz tempo. Tal assertiva coaduna-se com a moderna Teoria dos Sistemas, já comentada anteriormente. A empresa, como sistema autônomo, tem que funcionar sem o caráter personalíssimo que é próprio da atividade autônoma. A atividade empresária, levada a cabo pela capacidade sistêmica de auto governar-se, subsiste sem o empresário pessoa natural (homeostase). Destaca Andrea Guaccero (1999, p.12, tradução nossa) que conceito semelhante é admitido por parte minoritária da doutrina italiana:

Para existir uma empresa é necessária a criação de um organismo econômico, como entidade objetiva, que em qualquer modo se autonomiza com respeito ao seu criador (o empreendedor). Aquela organização elementar dos fatores produtivos, centrada essencialmente no trabalho do sujeito agente é própria da pequena empresa, que porém está fora da noção de empresa.

Gastone Cottino (2000, p. 161) traz luz a esta discussão e afirma que a empresa pode sobreviver à pessoa física do empreendedor (participação pessoal na gestão da empresa), como de fato ocorre amiúde. Os exemplos das fábricas abandonadas auto geridas pelos empregados demonstram que a presença do empresário não é decisiva nas realizações do processo produtivo. A respeito do tema, o Tribunal de Justiça de Santa Catarina 
(TJSC) possui julgado recente, onde o desembargador relator, ao decidir sobre o caráter empresarial de clínica médica para efeito de cobrança de ISS, excertou parte da sentença a quo, na qual o critério da essencialidade é discutido. In verbis:

[...] Claro que uma sociedade formada de profissionais liberais pode ser vista como uma sociedade empresária. Isso ocorrerá quando a atividade de origem dos seus sócios passe a ser somente um "elemento da empresa", como adverte o art. 966, p. único. Seria, por exemplo, a hipótese de um hospital mantido por pessoa jurídica constituída por dois médicos. Ali o labor intelectual de cada um dos especialistas ficaria esmaecido. A massificação dos atendimentos, a necessidade de contratação de outros profissionais da saúde e assim por diante levariam a sobrelevar a intenção meramente empresarial. Nesse caso, a sociedade mantenedora do hospital poderia ser indiferentemente mantida por médicos ou por quaisquer pessoas. Diferente a situação quando os mesmos dois médicos formam uma sociedade, mas continuam se dedicando à mesma atividade de origem. Então, permanecem atendendo diretamente os pacientes; o serviço prestado não é anônimo, mas pessoal dos médicos; o concurso de auxiliares (enfermeiros, secretários, atendentes) é exclusivamente coadjuvante. O caráter liberal da profissão permanece. A intenção, ao ser formada a sociedade simples, é tão-somente no sentido de conjugar esforços para a melhor qualificação dos serviços. (SANTA CATARINA, 2006, grifo nosso).

Percebe-se, nos trechos grifados da jurisprudência colacionada, que o juiz a quo, utiliza o critério da não essencialidade do empresário para caracterizar a atividade empresarial. Explica que o hospital do exemplo, por ser empresa, poderia ser mantido pelos médicos sócios ou por quaisquer pessoas. 


\subsection{A empresa concebida como um sistema}

A empresa se concretiza na atividade do empresário, e, como afirma Rubens Requião (2000, p.59): "Desaparecendo o exercício da atividade organizada do empresário, desaparece, ipso facto, a empresa”. Maria Helena Diniz (2006, p.755) aduz que:

Toda atividade empresarial pressupõe o empresário como sujeito de direitos e obrigações e titular da empresa, detentor do poder de iniciativa e de decisão, pois cabe-lhe determinar o destino da empresa e o ritmo de sua atividade, assumindo todos os riscos, ou seja, as vantagens e o prejuízo.

O conceito de Diniz admite a essencialidade do empresário na existência da empresa. Esta concepção é contestada por Gastone Cottino (2000, p.160), objeto de comento no tópico anterior.

Conforme entendimento de Fábio Ulhoa Coelho (2007, p.3) "o empresário é o indivíduo vocacionado à tarefa de combinar e articular os fatores de produção", que segundo o autor são quatro: capital, mão de obra, insumo e tecnologia. É ele quem, movido pelo lucro, vai estruturar as empresas, tratadas por Coelho como "organizações econômicas especializadas na produção de bens e serviços".

Fábio Ulhoa Coelho (2007, p.20) admite que, tratando-se de sociedade, a pessoa jurídica que a personifica é que é empresária e não as pessoas físicas de seus sócios. Estes podem ser empreendedores ou investidores. "Os empreendedores, além do capital, costumam devotar também trabalho à pessoa jurídica, na condição de seus administradores, ou as controlam. Os investidores limitam-se a aportar capital". O autor distingue os conceitos de empreendedor e empresário.

$\mathrm{Na}$ mesma esteira, Alberto Trabucchi (1964, p.311) sustenta que, em relação ao ordenamento jurídico italiano, a possibilidade de tornar-se empresário ${ }^{11}$ não se limita às pessoas

11 Neste caso, tradução direta de imprenditore, pois a doutrina italiana parece não distinguir os significados das palavras impresario e imprenditore, como faz Fábio Ulhoa Coelho em relação a empresário e empreendedor. 
físicas. Também as pessoas jurídicas podem sê-lo, como realmente sucede com as sociedades.

Ambos tocam em um ponto sensível do conceito expresso no art. 966 do CC, pois nada impede que a tarefa de organizar os fatores de produção seja realizada por intermédio de executivos ou consultores. Nesta hipótese, o capitalista que contratou os executivos (ou consultores) deve ser considerado investidor. A figura do empresário que organiza os fatores de produção está sendo exercida pela própria organização, através dos seus executivos. Estes são meros subordinados da estrutura (representada normalmente por um conselho de administração) e não podem ser considerados empresários.

Percebe-se, portanto, que a organização pode ser compreendida sem a figura do empresário que organiza os fatores de produção diretamente (essa tarefa foi delegada pelo investidor aos executivos/consultores). Até porque, uma vez organizados, tais fatores de produção comportam-se como um sistema autônomo (organismo), adquirindo vida própria independente da existência de qualquer empresário pessoa física e com uma função social. O sistema em si cumpre o exercício do empresário. Esta forma de conceber a empresa deriva da Teoria dos Sistemas. Com efeito, essa forma de ver a empresa, como sujeito de direito, é sustentada por Jorge Rubem Folena de Oliveira (1999, p.130), que afirma:

Com o surgimento das macroempresas, os empresários saíram do centro de decisão daquelas organizações, passando as empresas a terem vida própria, independentemente da decisão dos seus donos, que são vistos e tidos como meros investidores de capitais. Porém essa conseqüência fática ainda é pouco percebida nas legislações vigentes, as quais tratam a empresa, não como um ente titular de direitos e obrigações, mas como mero objeto de direito, isto é, como um elemento de propriedade do empresário. 
Por este ponto de vista, a pessoa jurídica deveria representar a empresa e não apenas a sociedade. Ou seja, compreendendo a empresa como um sistema, também a firma individual deveria ser considerada uma pessoa jurídica.

\section{CONCLUSÃo}

Para o CC, a atividade empresária é a organização dos fatores de produção realizada com profissionalismo, isto é, com habitualidade e pessoalidade. Quem realiza essa organização é o empresário. $\bigcirc$ mesmo diploma reserva à atividade empresária uma série de direitos e obrigações com o intuito de preservar a segurança das relações econômicas em uma área tão sensível do ponto de vista social. Além das prerrogativas previstas no CC, que protegem o patrimônio empresarial, as empresas estão sujeitas a um regime de tributação diferenciado e são protegidas na sua perpetuação pela Lei de Falências. A contrapartida é a publicidade legal dos seus atos e situação econômica, para dar segurança às operações de crédito. Todavia, o conceito expresso no Código é carregado de subjetivismo. Apesar de representar avanço considerável do ponto de vista de ciência do direito, não cumpre com perfeição seu objetivo de definir quem é empresa e quem não é. Fornece pistas fundadas em uma realidade econômica. Esta insegurança conceitual resulta na distribuição injusta de direitos, mais que deveres, para quem não é de fato empresa.

Por sua vez, os doutrinadores do direito também não logram êxito em encontrar um conceito jurídico de empresa mais objetivo que aquele já codificado. $\mathrm{O}$ enfoque sistêmico, que concebe a empresa como um organismo autônomo, possibilita um novo critério para a sua identificação: a essencialidade da atividade laborativa do empresário para a subsistência da empresa. Isto é, se a organização prescindir da pessoa natural dos empreendedores para sobreviver, pode ser considerada uma empresa. Se não prescindir, a atividade não é empresária, como é o caso de uma sociedade simples, por exemplo, entre um engenheiro e um arquiteto, 
onde somente a unidade sinérgica daquelas personagens específicas permite a existência da organização. Outro exemplo ilustrativo é o de um tradutor que realiza seu trabalho contando apenas com uma secretária. Se ele deixar de existir, perece também a pseudo-empresa de traduções. Ou seja, sua essencialidade caracteriza a atividade não empresária.

Aspecto importante para a caracterização da atividade empresária é a presença ou não da exploração do trabalho alheio. A simples presença de colaboradores, como no exemplo acima, não faz com que uma atividade seja empresária. Entretanto, é difícil conceber-se a atividade empresária sem o envolvimento de trabalho alheio. Para deixar claro o conceito, um derradeiro exemplo. Imagine-se um empresário individual (que por força do CC não é pessoa jurídica) que possua um estacionamento. É empresário, pois organizou os fatores de produção: terra, capital e, principalmente, trabalho de outrem. Se há um gerente nesta empresa, é fácil concluir que o negócio continuará existindo independentemente da presença do empresário. Logo, há uma empresa, organismo independente cujo objetivo intrínseco é sobreviver, como todo organismo. Neste caso, o empresário deixou de ser a pessoa física e passou a ser a força homeostática da organização.

O caráter de impessoalidade, ou não essencialidade da ingerência direta do empreendedor, também evidencia a existência de uma pessoa jurídica autônoma, com interesses próprios. E, admitindo-se esta concepção, é razoável aceitar que deveria também ser estendida aos empresários individuais a personificação do seu negócio. Esta abstração passa a fazer sentido ao considerar-se a importante função social da empresa e a necessidade da proteção estatal à sua continuidade. No ordenamento atual, a empresa individual fenece junto com o seu proprietário.

Em uma concepção sistêmica, a empresa, ainda que unipessoal, assemelha-se em tese, à figura da fundação, pessoa jurídica para o CC. Por analogia, os bens da fundação podem ser compa- 
rados ao estabelecimento empresarial, com a diferença que este último é exigível, a qualquer tempo, pelos proprietários, no limite da sua liquidez. Na fundação os bens estão organizados a serviço de uma causa. Na empresa, estão organizados a serviço de um objeto social, como defende a Teoria Institucionalística.

A importância destas reflexões reside na necessidade de prospecção de novos paradigmas que atendam as realidades fáticas que se apresentam com velocidade extraordinária no mundo econômico. $\mathrm{O}$ direito tem que acompanhar com a mesma agilidade a natureza mutante dos organismos e estruturas produtoras de riquezas e empregos, sob pena de constituir-se em óbice para o progresso da sociedade. O critério para identificação da atividade empresária, aventado neste artigo, baseado na não essencialidade da presença física do empresário, ainda não preenche o ideal da parametrização objetiva, porém abre uma nova perspectiva para a observação do fenômeno empresarial, cujo aprofundamento pode ser objeto de futuros trabalhos científicos.

\begin{abstract}
This article features the Systems Theory, that provides a theoretical bases for a new parameter to identify the existence of a firm, relevant fact in the legal world. Once the firm is admitted as an autonomous body, its existence can be assessed by the essential criterion of the physical figure of the entrepreneur.
\end{abstract}

Keywords: Entrepreneurial activity. Commercial law. Company. Theory of the firm. Systems Theory.

\title{
REFERÊNCIAS
}

AIROLDI, Giuseppe; BRUNETTI, Giorgio; CODA, Vittorio. Lezione di economia aziendale. Bologna: Il Mulino, 1989.

ASQUINI, Alberto. Perfis da empresa. Tradução de Fábio Konder Comparato.

Revista de Direito Mercantil. São Paulo, n.104, p.108 - 126, out/dez.1996. 
BRASIL, Presidência da República. Lei n. 10.406, de 10 de janeiro de 2002. Código Civil. Brasília, DF: Senado, 2002. Disponível em: <http:// www.planalto.gov.br/CCIVIL/leis/2002/L10406.htm>. Acesso em: 23 out. 2007.

, Superior Tribunal de Justiça. Recurso Especial n. 623.367/RJ. Recorrente: Município de Rio de Janeiro. Recorrido: Escritório Central de Arrecadação e Distribuição. Relator Min. João Otávio de Noronha. Julgado em 15 jun. 2004. DJU de 9 ago. 2004. Disponível em: <http:// www.stj.gov.br/webstj/Processo/Justica/detalhe.asp?numreg=20040006400 $3 \& \mathrm{pv}=000000000000>$. Acesso em: 23 out. 2007.

BULGARELLI, Waldírio. Tratado de Direito Empresarial. 2.ed. São Paulo: Atlas, 1995.

CAMPOBASSO, Gian Franco. Diritto Commerciale. Diritto dell'impresa. 3. ed. Torino: UTET, 1997.

CHIAVENATTO, Idalberto. Introdução à Teoria Geral da Administração. 4. ed. São Paulo: Makron Books, 1993.

COELHO, Fábio Ulhoa. Parecer. Exarado para o Instituto de Registro de Títulos e Documentos e de Pessoas Jurídicas do Brasil. São Paulo, 2003. Disponível em:

< http://www.irtdpjbrasil.com.br/parecerfabio.htm>. Acesso em: 25 set. 2007.

. Comentários à nova lei de falências e de recuperação de empresas: Lei n. 11.101, de 9/2/2005. 3. ed. São Paulo: Saraiva, 2005. . Manual de Direito Comercial. 18. ed. São Paulo: Saraiva, 2007. COTTINO, Gastone. L’imprenditore. 4. ed. Padova: Cedam, 2000.

DINIZ, Maria Helena. Código Civil anotado. 12. ed. São Paulo: Saraiva, 2006.

EATON, Curtis; EATON, Diane. Microeconomia.Tradução de Cecília Bartalotti. 3. ed. São Paulo: Saraiva, 1999.

FLORIANÓPOLIS/SC, Lei Complementar n. 07, de 18 de fevereiro de 1997. Consolidação das leis tributárias do município de Florianópolis. Florianópolis, SC: Câmara Municipal, 1997. Disponível em: <http://www. cmf.sc.gov.br>. Acesso em: 23 out. 2007. 
GUACCERO, A. Organizzazione. In: BAVETTA, C.; DI CECCO, G.; MANGANO, R.; MELINA, M.; PERRINO, M.;TERRANOVA, Giuseppe (org). Diritto Commerciale I. L'impresa. Casi e problemi presentati. Torino:Giappichelli, 1999.

GUITTON, Henri. Economia política. Tradução da edição original francesa de 1956 por Oscar Dias Corrêa. 2.ed. Rio de Janeiro: Fundo de Cultura, 1961.

HALL, Robert; LIEBERMAN, Marc. Microeconomia - princípios e aplicações. Tradução de Luciana Michelino. São Paulo: Pioneira Thomson Learning, 2003.

HOUAISS, Antônio e VILLAR, Mauro. Dicionário Houaiss da língua portuguesa. Rio de Janeiro: Objetiva, 2007.

ITÁLIA, Codice Civile, Costituzione e leggi speciali. Milano: Giuffrè, 1991.

LANGE, Dílson França. Uma visão sistêmica do Direito de Empresas no novo Código Civil. Rio de Janeiro: Temas \& Idéias, 2005.

MARCONDES, Sylvio. Questões de Direito Mercantil. São Paulo: Saraiva, 1977.

MARTINS, Fran. Curso de Direito Comercial. 22. ed. Rio de Janeiro: Forense, 1996.

OLIVEIRA, Jorge Rubem Folena de. A empresa: uma realidade fática e jurídica. Revista de Informação Legislativa, Brasília, ano 36, n. 144, p.111136, out./dez. 1999.

REQUIÃO, Rubens. Curso de Direito Comercial. 24. ed. São Paulo: Saraiva, 2000.

ROCHA, Joseilton e SELIG, Paulo Maurício. O uso de indicadores de desempenho como base para remuneração variável nas empresas e suas influencias nos custos. In: Congresso Brasileiro de Custos. São Leopoldo, RS, 2001. Anais.

ROMEO, Antonino. Diritto Commerciale. Bresso: Tramontana, 1985.

RULLANI, Enzo. Teoria ed evoluzione dell'impresa industriale. In:

RISPOLI, Maurizio (org). L'impresa industriale. Bologna: Il Mulino, 1983. 
SANTA CATARINA, Tribunal de Justiça de Santa Catarina. Apelação Cível n. 2006.003326-5, da Capital. Apelante: Ortoclini Ultrasom Ltda. Apelado: Município de Florianópolis. Relator: Des. Orli Rodrigues. Julgado em 28 mar. 2006.

Disponível em <http://tjsc6.tj.sc.gov.br/jurisprudencia/ VerIntegraAvancada.do>.

Acesso em 07 out. 2007.

SEBRAE/SP. Serviço Brasileiro de Apoio à Pequena e Média Empresa de São Paulo. O que é melhor, ser autônomo ou empresa? Disponível em: <http://www.sebraesp.com.br//principal >. Acesso em: 15 out. 2007.

TRABUCCHI, Alberto. Instituzioni di Diritto Civile. 14. ed., Padova: Cedam, 1964.

VARIAN, Hal. Microeconomia - princípios básicos. Tradução da 4. ed. americana por Ricardo Inojosa. Rio de Janeiro: Ed. Campus, 1999. 
